\title{
ОТНОСИТЕЛЬНЫЕ ВРЕМЕНА УДЕРЖИВАНИЯ УГЛЕВОДОРОДОВ В ГАЗОХРОМАТОГРАФИЧЕСКОМ АНАЛИЗЕ.
}

\author{
Ю. ЭЙЗЕН \\ О. КИРРЕТ,
}

член-корреспондент Академии наук Эетонской ССР

О. ЭИЗЕН,

кандидат технических наук

При разделении сложных углеводородных смесей и определении нндивидуального состава жидких топлив авторы использовали аналитический и препаративный метод газохроматографни. В качестве стационарной жидкой фазы (СЖФ) применяли днфеннлформамид и $\beta-, \beta^{\prime}$-тиодипропионитрил, синтезированные в лаборатории Института хнмии АН ЭССР, и полиэтиленгликоль 4000 фирмы Мерк. В настоящей работе приводятся данные об относительных. временах удерживания различных парафнновых, олефиновых н ароматических углеводородов $\mathrm{C}_{5}-\mathrm{C}_{12}$ на названных СЖФ.

Исследование проводилось на газохроматографе УХ-1 Таллинского завода нзмерительных прнборов. Во избежание перегрузки колонок подача пробы производндась микрошприцем Гамилтона, в количестве $0,1-0,5 \mu л$. В качестве газа-носителя использовался водород со скоростью $60 \mathrm{M} /$ мин, при начальном давлении $1,5-2,0 \kappa \Gamma / \mathrm{cm}^{2}$. Спиральные колонки изготовлялись из медной трубки внутренним диаметром в 4 мм. Определение относительного времени удерживания проводнлось при температурах 100 , 150 и $180^{\circ} \mathrm{C}$ в соответствин с СЖФ и исследуемыми соединениями. Температура поддерживалась постоянной с точностью $\pm 0,2^{\circ}$.

Время удерживания определялось по пику воздуха, выпускаемого в колонку вместе с пробой.

Относительное время удерживания $S$ рассчитывалось по формуле: $S=\frac{a x-a v}{a b-a v}$, где $a x$ - время удерживания исследуемого компонента; $a b-$ время удерживания бензола; $a v-$ время удерживания воздуха.

Образцы углеводородов были частично получены из магазинов Союзреактива, большая же часть их была синтезирована в нашей лабораторни ${ }^{\text {. }}$.

Таблища !

Характеристика колонок, применявшихся при определении относительных времен удерживания углеводородов

\begin{tabular}{|c|c|c|c|}
\hline Колонка & № 1 & № 2 & № 3 \\
\hline Жндкая фаза & $\begin{array}{c}\text { Дифенилформамид } \\
20 \%\end{array}$ & $\begin{array}{l}\beta-, \quad \beta^{\prime} \text {-Тноднпро- } \\
\text { пионитрил } 20 \%\end{array}$ & $\begin{array}{l}\text { Полнэтнленгли- } \\
\text { коль } 400020 \%\end{array}$ \\
\hline Твердая фаза & $\begin{array}{l}\text { Диатомитовый } \\
\text { кирпич } 0,2-0,4 \text { м. }\end{array}$ & $\begin{array}{l}\text { Диатомитовын̆ } \\
\text { кирпич } 0,2-0,3 \text { м.м }\end{array}$ & $\begin{array}{l}\text { Диатомитовый } \\
\text { кирпич } 0,2-0,3 \text { мм }\end{array}$ \\
\hline Длина, & 3,0 & 6,0 & 6,0 \\
\hline $\begin{array}{l}\text { Чнсло теоретических } \\
\text { тарелок по толуолу }\end{array}$ & $2000^{2}$ & $4000^{3}$ & $3400^{2}$ \\
\hline $\begin{array}{l}\text { Температура колонки, } \\
{ }^{\circ} \mathrm{C}\end{array}$ & 100 & 100,150 & $100,150,180$ \\
\hline
\end{tabular}

1 Синтез был проведен научными сотрудннками В. Каск, Э. Уск, И. Пыдер.

2 Определено при $100^{\circ}$.

3 Определено при $150^{\circ}$, 
Таблища 2

Относительные времена удерживания углеводородов на дифенилформамиде, $\beta-, \beta^{\prime}$-тиодипропионитриле и полигликоле 4000

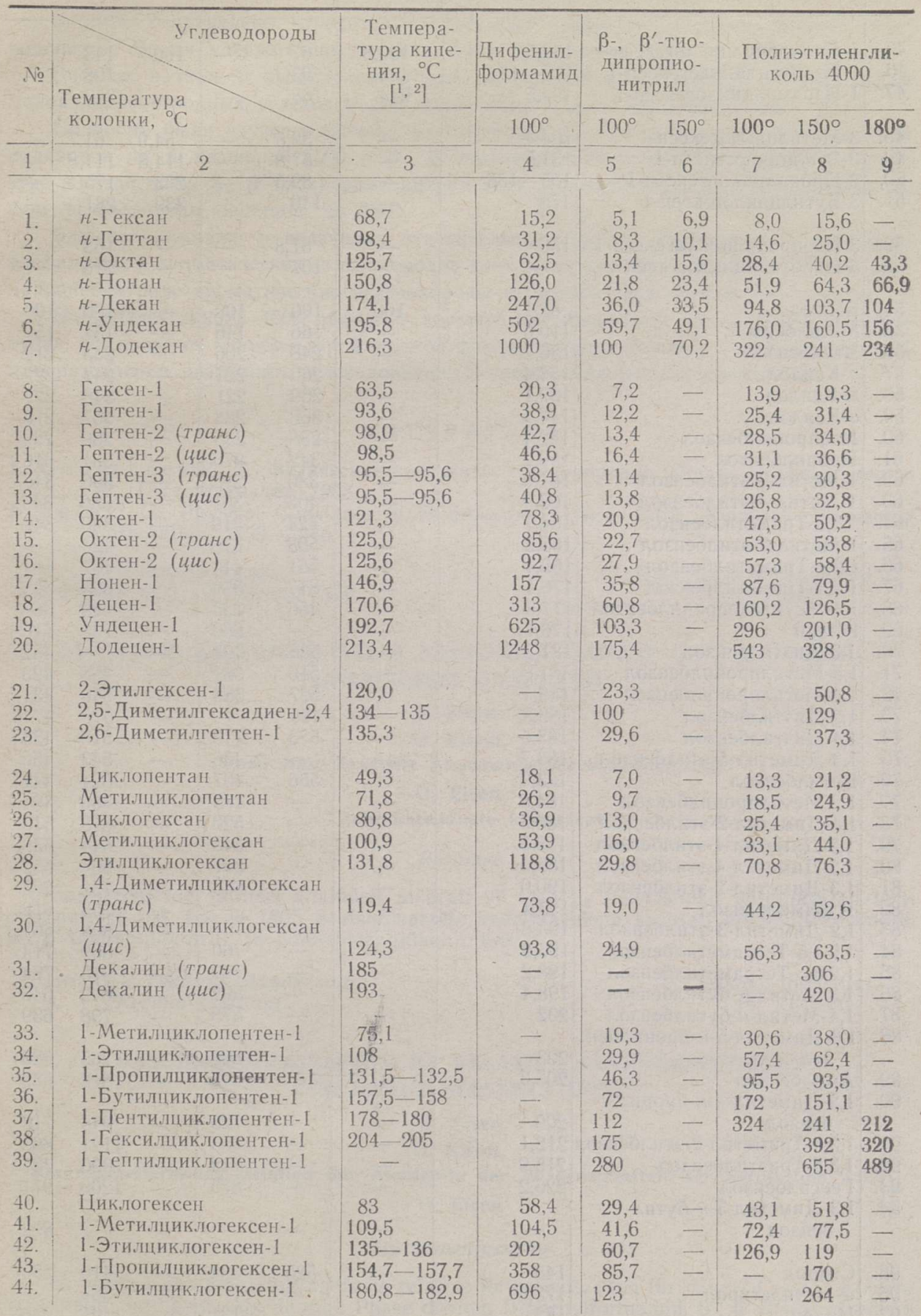


Продолжение таблиць 2

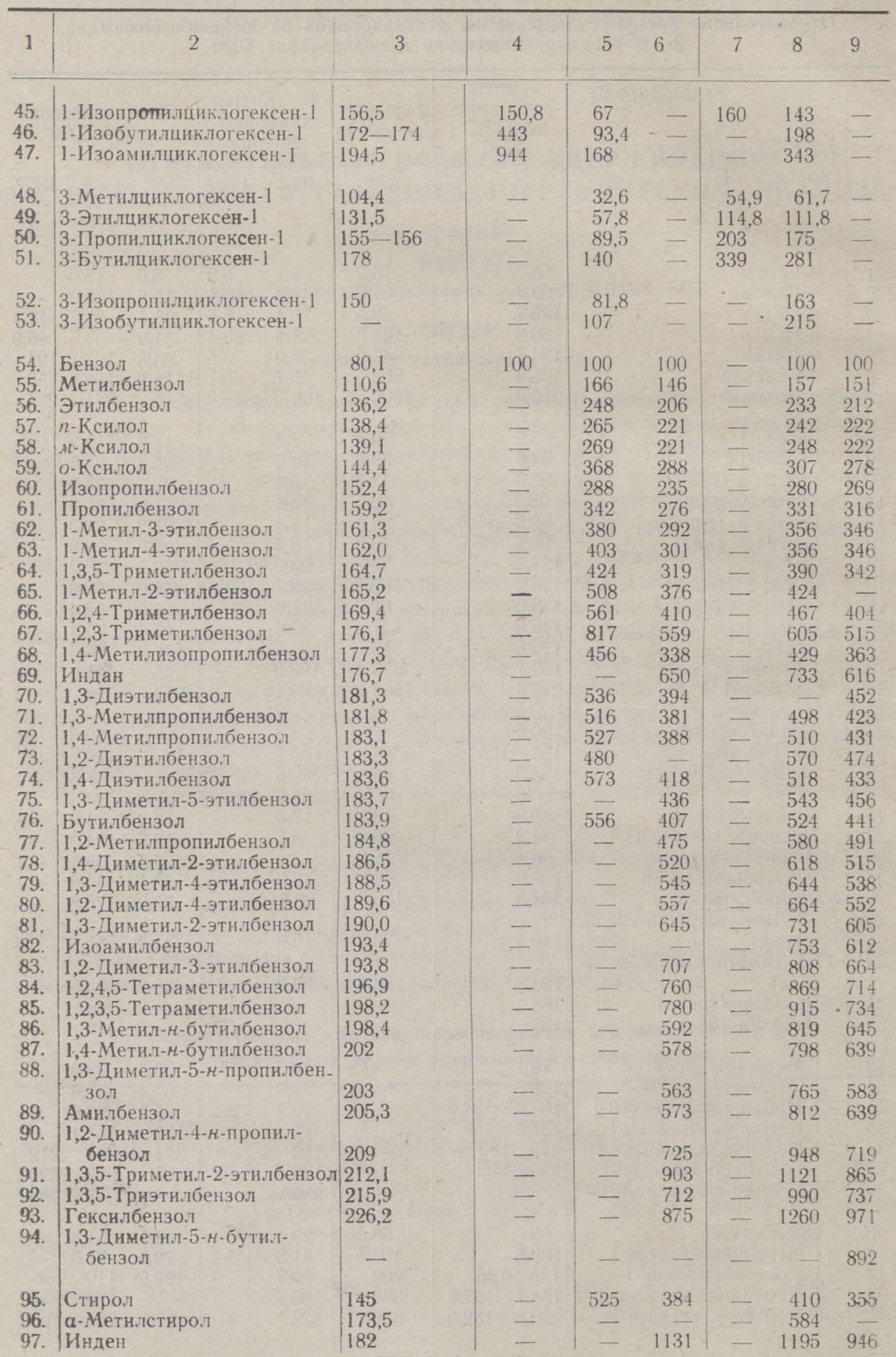


Чнсло теоретнческих тарелок $n$ вычнслялось по нзвестной формуле

$$
n=5,54\left[\frac{t r}{w}\right]^{2}
$$

В табл. 2 приведены относительные времена удерживания исследованных углеводородов. Время удерживания бензола было принято за 100.

Впервые в табл. 2 приводятся данные об относительных временах удерживания моноалкилпроизводных углеводородов циклогексенового и циклопентенового ряда.

Подробно были изучены времена удерживания $\mathrm{C}_{9}-\mathrm{C}_{10}$ алкилароматических углеводородов на полигликоле 4000 и $\boldsymbol{\beta}$-, $\boldsymbol{\beta}^{\prime}$-тиодипропионитриле. Применяемый в качестве жидкой фазы $\beta$-, $\beta^{\prime}$-тиодипропионитрил дает возможность определять ароматические углеводороды, кипяние до $200^{\circ}$.

Большое различие в величинах относительных времен удержнвания парафиноолефиновых и ароматических углеводородов дает возможность определять на $\beta$-, $\beta^{\prime}$-тио. дипропионитриле ароматические углеводороды в качестве самостоятельной группы.

Полиэтиленгликоль 4000 обладает хорошей устойчивостью при высоких температурах. Он является универсальной жидкой фазой, которую можно с успехом применять для разделения различных углеводородов, а также кислородных соединений.

\title{
ЛИТ Е Р А Т У P A
}

1. Обо оленцев Р. Д., Физические константы углеводородов жидких топлив и масел М., Гостоптехнздат, 1953.

2. E g l of f G., Physical Constants of Hydrocarbons. New York, Reinhold Publishing Corporation, $1939-1946$.

\author{
Ннститут химии \\ Акадении наук Эстонской ССР \\ Поступила в редакцию \\ 14 XI 1963
}

\section{SÜSIVESINIKE SUHTELISTEST VÄLJUMISAEGADEST GAASIKROMATO- GRAAFILISEL ANALUUSIL}

\author{
J. Eisen \\ O. Kirret, \\ Eesti NSV Teaduste Akadeemia korrespondentliige \\ O. Eisen, \\ tehnikateaduste kandidaat
}

Resümee

Gaasikromatograafilisel analüüsil määrati $97 \mathrm{C}_{5}-\mathrm{C}_{12}$ süsivesiniku väljumisajad temperatuuridel $100,150 \mathrm{ja} 180^{\circ}$. Statsionaarsete vedelfaasidena kasutati difenüülformamiidi, $\beta$-, $\boldsymbol{\beta}^{\prime}$-tiodipropionitriili ja polüetüleenglükooli 4000 .
Eesti NSV Teaduste Akadeemia
Keemia Instiluut
Saabus toimetusse
14. XI 1963

\section{GASCHROMATOGRAPHISCHE RELATIVE RETENTIONSZEITEN DER KOHLENWASSERSTOFFE}

\author{
J. Eisen \\ O. Kirret, \\ Korrespondierendes Mitglied der Akademie der Wissenschaften der Estnischen S.S.R. \\ O. Eisen
}

\section{Zusammenfassung}

Es wurden gaschromatographische relative Retentionszeiten für den $97 \mathrm{C}_{5} \quad \mathrm{C}_{12}$ Kohlenwasserstoff bestimmt. Als flüssige Phase dienten Diphenylformamid, $\beta$-, $\beta$ '-Bis-propionitrilsulfid und Polyäthylenglykol 4000.

\footnotetext{
Institut für Chemie

der Akadenie der Wissenschaften der Estnischen SSR
}

Eingegangen

am 14. Nov. 1963 